\title{
Active Power Control in Modern Power System through Demand Side Response
}

\author{
Syed Afzal Shah ${ }^{1}$, Zafar Ahmad ${ }^{2}$, Israr Uddin ${ }^{3}$, Muhammad Nazeer ${ }^{4}$ \\ ${ }^{1,2,3,4}$ Department of Electrical Energy System Engineering, US-Pakistan Center for Advanced Studies in Energy \\ (US-PCASE), UET Peshawar \\ afxalshaw@gmail.com¹, zafar.ahmad619@gmail.com², israreng93@gmail.com ${ }^{3}$, muhammadnaxeer@gmail.com ${ }^{4}$ \\ Received: 09 December, Revised: 19 December, Accepted: 25 December
}

\begin{abstract}
Integration of renewable energy sources in power system has increased rapidly in recent years due to environmental effects such as climate change and global warming. Renewable sources provide clean and sustainable energy but it has some negative effects on power system. Renewable sources are mostly inertia-less sources and they increase instability in system. Frequency deviations are main indicator of their fluctuation because of their variable energy nature. To stabilize frequency, spinning reserves are there. Most of generators providing spinning reserves are fossil fuel generators, their operation is costly and not environment friendly. To minimize dependence on spinning reserves, demand side response is a method, which can provide frequency reserves cheaply and have a fast response. Demand side response is to shift loads of end users from peak hours to off-peak hours in response to frequency deviations or any contingency in power system with agreement with end users. This paper proposes the use of demand response through load management. Direct control method is used to control loads of end users. In response to frequency deviations, loads are $\mathrm{ON} / \mathrm{OFF}$ to stabilize the frequency. For that purpose, a simple microgrid is designed in MATLAB/SIMULINK comprises of Solar PV and diesel generation sources. Loads are controlled through simple controller, which monitor frequency and act accordingly. Different scenarios are simulated, with demand side response and without demand side response. The results showed that with demand side response, frequency can be stabilizing quickly and system can be prevented from instability.
\end{abstract}

Keywords - DSR, Frequency Reserves, Demand Response

\section{INTRODUCTION}

Stability and security of electrical power system is main concern of present as the population expanding rapidly so the demand of electricity as well. To contain the situation, new power generation sources are increasing in numbers. Mostly traditional generation sources are based on fossil fuels which are non-environmental friendly. Scarce of fossil fuels and growing concern of global warming and climate change the world is focusing on environmental friendly generation sources to tackle the problem of increasing demand. Apart from positive aspect of renewable sources, there are negative aspects which affect stability and security of power system. Since most of renewable sources are variable in nature and have less moving parts, their integration in power system affect frequency of the system. Fluctuation in system frequency occurs more regularly. These fluctuations in frequency often leads to instability of the system. Change in frequency is main indicator of temporary changes in supply and demand of power system [1]. Frequency rises when supply exceeds demand and it falls when demand exceeds supply. To control frequency of power system, there are spinning reserves which are used in case of contingencies. These spinning reserves are primary, secondary and tertiary reserves based on their time of response [2]. Spinning reserves are generating unit which are up and running but only contribute in case of contingency. So the operation cost of spinning reserves are high and these spinning reserves units are mostly fossil fuel based and are non-environmental friendly. Apart from these reserves, Demand side response (DSR) is an alternate way to control frequency of the grid and it is also cost effective.

Demand side response (DSR) is a response from loads to control any contingency related to frequency. Demand side response is to shift demand of end user to another time by agreement with the end user. End user can shift their loads from peak hours to off peak hours in case of under frequency. There is also economic benefit to it as tariff in off peak hours is less as compared to peak hours. Due to technological advancement world is shifting from traditional grid system to smart grids and demand side response is main feature of smart grids. Direct and indirect demand side response are main strategies based on its response type. In indirect strategy, the utility has no control over devices at end user side. It is generally based on tariffs and incentives. Utility forecast tariffs for day ahead to encourage end users to shift their loads according to these tariffs best suited to end users. Incentive based DSR is to encourage consumers to shed their loads in case of contingency in exchange for rewards in term of economics.

In this paper Direct demand side response strategy is considered. In direct DSR, utility has complete control over end user's devices. Utility can on/off devices according to its requirement. When there is peak time and generation is unable to handle the demand, the frequency of the system begins to fall, then to control frequency deviation utility can off some noncritical loads at consumer side to bring frequency back to its 
nominal value. A centralized controller is used, which generates signal according to frequency deviations and then send a signal to the devices at end user side, which have preset values. It can turn on/off the load according to preset value. In this method reserves can be provided by load management quickly and at low cost than spinning reserves and dependence on spinning reserves can minimized. In recent years, demand side response has gain a lot of interest due to its technical and economic benefits.

\section{RELATED WORK}

The following scientific research proposes different strategies based on load management to better understand the concept and usage of demand side response. In [3], various strategies are considered for air conditions and refrigeration system and their contribution in demand side response. Incentive based and Time of use (TOU) based DSR are discussed and their reliability and implementation of demand response strategy is discussed. Assessment of DR and its application in china for the future is taken under study. Different strategies for the usage of air conditions and refrigeration system in DR are provided which can be used separately or in combination with one another.

In [4], contribution and effectiveness of DSR on residential load in Switzerland is discussed. Apart from industrial and commercial loads, participation of residential loads in demand response program is proposed. The survey is carried out on 30 utilities in Switzerland for data collection. DSM opportunities within residential load are identified. The impact of DSM on economic cost reduction per customer is obtained. The author discussed that residential load have very small effect in DSM but large number of residential customers can have major impact in Demand response program.

In [5], DSM opportunity in Refrigeration system in Turkey is discussed. The economic impact on customers by using refrigerators in DR program is analysed. The working of refrigerator model and its consumption throughout a week is explained. Direct load control method for refrigeration system is used. By changing working time of refrigerator from high demand period to low demand period, cost optimization is carried out and are compared in multiple and single pricing tariffs.

In [6], load control method for renewable energy resources is discussed. Load control method is used on basis of frequency and voltage sensors. Microcontroller is used to monitor the frequency and voltage deviation and take decision on basis of those measurements to connect or disconnect the loads. Software is designed for voltage and frequency monitoring and tested on $18 \mathrm{KW}$, single phase micro hydro system. For load switching fuzzy logic control system is developed which uses the input from algorithm which monitors voltage and frequency.

In [7], the impact of flexible load and wind power integration on power system imbalance is discussed. Cold storage rooms are considered as flexible loads as they can provide demand response. The author proposed that cold storage rooms as flexible loads can provide reserves of $90 \mathrm{MW}$ through automatic governor control (AGC) in Danish power system. The cold storage room is designed in this study. AGC is used to monitor the frequency deviations. The reserves provided by Cold storage rooms can reduce dependency on spinning reserves generators and can provide stability to power system.

In [8], a stochastic programming model is developed for optimal performance of smart microgrid to reduce the operation cost and reduce the emission by usage of renewable energy sources. To resolve uncertainties from renewable sources, DR program is used in which industrial, commercial and residential consumers participate. Incentive based DR program is used. Multi-objective purpose particle swarm optimization (MOPSO) based on fuzzy logics is used in the study. The study shows that using Demand response program the operating cost and pollution is reduced by considerable amount.

In [9], a method to reduce the peak load of residential community by use of HAN system is proposed. The HAN devices are installed at end user. The main component of HAN system is HAN controller which analysis signal both utility and end user. The device uses two-way communication and the utility gets inform of actual load reduction at end user by HAN controller. The algorithm is developed by using UML (unified modelling language) and implemented in HAN controller in form of filed programming gate array (FPGA) device. The study shows that participation of large number of residential consumers in DR event can significantly reduce peak load and can support grid in case of instability such as under frequency situation

The scientific research in [10] [11] [12] [13] also proposes different strategies for load control and contribution of responsive loads and their impact in power system. Strategies are proposed to provide primary frequency reserves in power system through smart load management.

\section{METHODOLOGY}

In this paper, model of microgrid is considered which uses Distributed energy resources Solar PV and diesel generator is also used for reliability of the system. Microgrid has been modelled in MATLAB/Simulink and it includes a $300 \mathrm{KW}$ of Solar PV plant and $1 \mathrm{MW}$ Diesel generator in generation side along with its required converters and transformers.

\section{A. Diesel Generator Model}

The generator modelled in microgrid is three phase synchronous machine which generates rated power of $1 \mathrm{MW}$ at $60 \mathrm{~Hz}$ frequency. The generator increases or decrease output according to demand and supply. The diesel generator is directly connected to main transmission line.

\section{B. Loads and Controller Model}

In Simulink model, loads with different consumptions are used. Initially the load on the system is $1200 \mathrm{KW}$ but later the load is increased to $1400 \mathrm{KW}$ to create peak scenario. Three phase circuit breakers are used for switching purpose for loads. Signal for breaker is received from controller to whether open the switch or closed it. The controller is basically designed for frequency control. Grid frequency is taken as input signal to 
controller. Set points for frequency are defined in controller, when frequency exceeds from these points, the controller generates signal for breakers to operate. The controller is designed for under frequency and over frequency situation. It is designed to give support to the system through load management in case of under and over frequency.

\section{SimUlation AND RESUlts}

The model comprises of Solar PV and Diesel generator along with resistive load and a controller. Working of these components and results are explained. Solar PV and diesel generator have rated power of $300 \mathrm{KW}$ and $1 \mathrm{MW}$ respectively. Total resistive load is $1200 \mathrm{KW}$ initially. A controller is designed for frequency monitoring and stabilizing the frequency. The frequency for the system in this model is $60 \mathrm{~Hz}$. The threshold for frequency control is set at $59 \mathrm{~Hz}$ and $61 \mathrm{~Hz}$ for lower and higher limit respectively. The main purpose of controller is peak shaving in under frequency situation. When the load is increased, and peak occurs. The frequency begins to drop. When frequency crosses lower limit at $59 \mathrm{~Hz}$. The controller cut off supply to some loads to contain frequency at $59 \mathrm{~Hz}$. In this way the momentary deviation of frequency due to peak demand is contained.

Peak shaving through load management is part of demand response program. The study proposes active power control through demand side response. To show the effect of demand response by peak shaving of load to stabilize the frequency, different scenarios are considered in the simulations.

\section{A. Frequency response without Demand response}

In this scenario, the controller will keep the circuit breaker closed in order to observe the response of frequency of the system. Loads will not be cut off in this scenario. Initially the load on the system is $1200 \mathrm{KW}$. When frequency stabilizes after transient state, the load is increased at $20^{\text {th }}$ second of simulation time to generate peak demand situation. Frequency of the system begins to drop as the demand is increased. At 22 second the frequency crossed the threshold point of frequency. Without frequency reserves and Demand response the frequency continues to drop and the system goes to instability as shown in figure 1 .

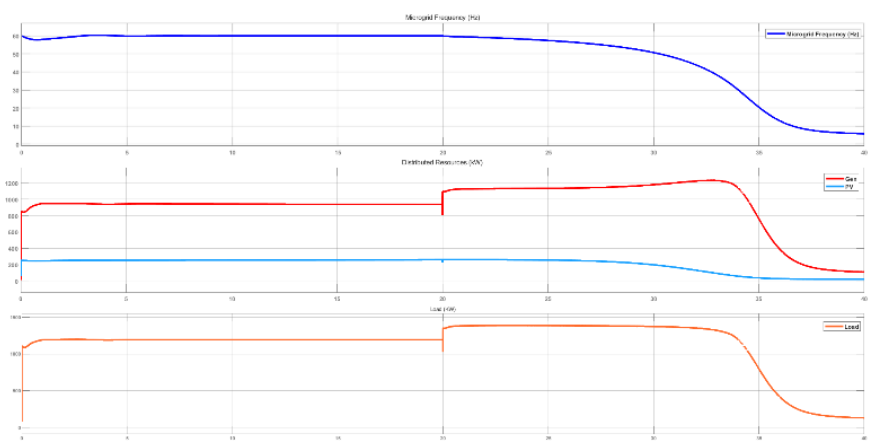

Figure 1. Frequency response without Demand response

\section{B. Frequency response with Demand response}

In this scenario, the simulation is carried out with using of demand response program. Direct control method is used to
ON/OFF the load by using simple controller. The initial load on the system is $1200 \mathrm{KW}$, out of which $1000 \mathrm{KW}$ is constant load and other two loads of $100 \mathrm{KW}$ each are connected to controller. These two loads will participate in DR program of peak shaving. Initially when simulations run, the system is in transient state because of diesel generators starting cycle. The steady state is achieved, and frequency stabilizes at $60 \mathrm{~Hz}$ at $9^{\text {th }}$ second. At 20 second the load is increased to $1400 \mathrm{KW}$ to generate peak situation for simulations. The frequency begins to drop and crossed the threshold at of $59 \mathrm{~Hz}$ at 22 second. When the frequency drops from $59 \mathrm{~Hz}$, the controller operates the circuit breakers at 22 second as shown in figure 2 . The controller cut off the supply to two $100 \mathrm{KW}$ loads. The frequency is contained at $59 \mathrm{~Hz}$ and frequency begins to rise at 23 second of simulation time. The momentary deviation of frequency is contained at $59 \mathrm{~Hz}$ and stabilizes the frequency back to $60 \mathrm{~Hz}$ at $29^{\text {th }}$ second of simulation time.

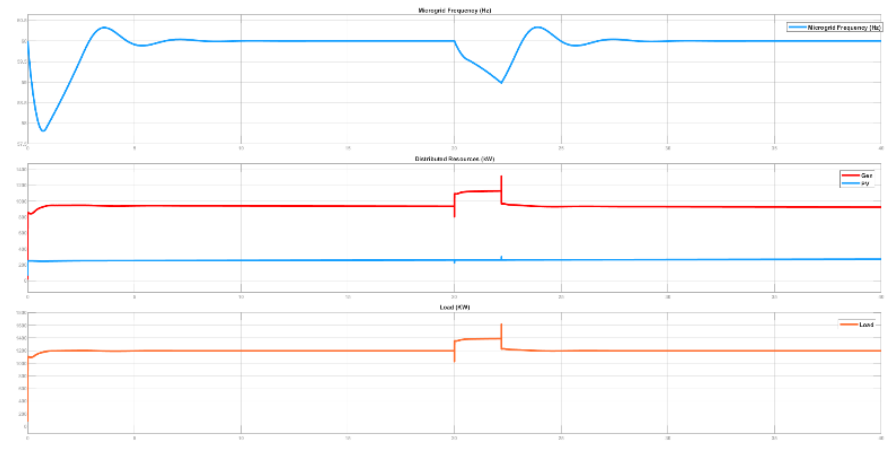

Figure 2. Frequency response with demand response

\section{Frequency response after generation loss}

In this scenario, the Solar PV is turned off to generate a situation of generation loss to observe characteristics of frequency. Initially generation of Solar PV is $300 \mathrm{KW}$ and Diesel generator generates $1 \mathrm{MW}$ power. The load connected to the lines are 1.2 MW. At time 20 of simulation time, Solar PV is cut off from generation side. Now the demand exceed generation. Demand is still 1.2 MW and generation is $1 \mathrm{MW}$. So the frequency begins to drop and without reserves and proper demand response, the frequency continues to drop until system goes into instability in matter of seconds as shown in figure 3 .

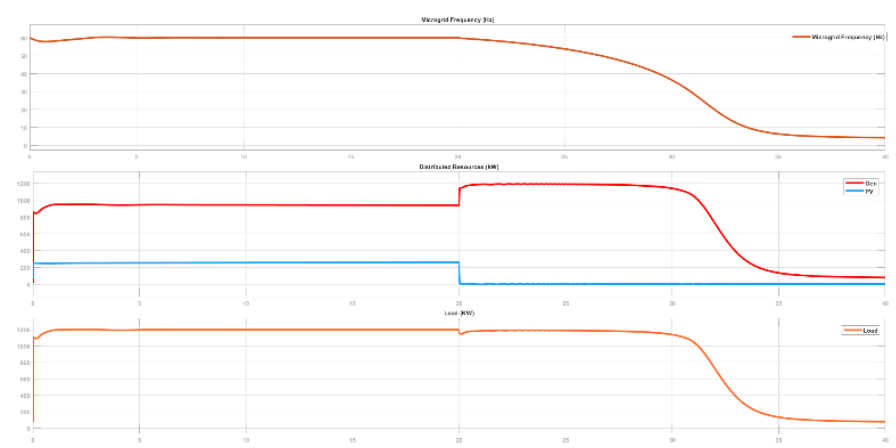

Figure 3. Frequency response after generation loss 


\section{Generation loss and Demand response}

In this scenario, Solar PV is cut off to generate a generation loss situation and to observe frequency response with the use of demand response. Initially load on the system is $1.2 \mathrm{MW}$ and generation of diesel generator and Solar PV is $1 \mathrm{MW}$ and 300 $\mathrm{KW}$ respectively. At time 20 of simulation time, Solar PV is cut off. Now the demand is more the generation and the frequency begins to drop. As the frequency approaches the threshold point of $59 \mathrm{~Hz}$, the controllable load of $200 \mathrm{KW}$ is turned off. Now the load is within limit of generation capacity and the frequency begins to rise at time 22 second. And the frequency stabilizes back to $60 \mathrm{~Hz}$ at $26^{\text {th }}$ second as shown in figure 4 .

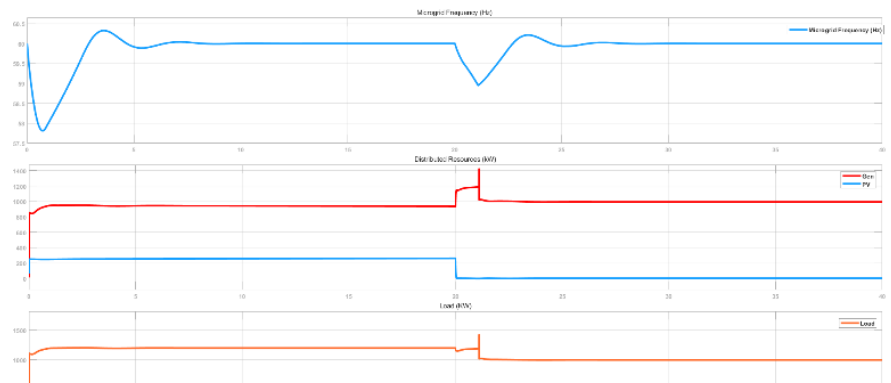

Figure 4. Frequency response after generation loss with demand response

As the results, shows in figure 2 and figure 4 that with use of demand side response the frequency stabilizes back to its normal value by switching OFF two loads of $100 \mathrm{KW}$. Peak is handled by switching these loads to stabilize the system. While in figure 1, when the peak occurred the frequency begins to drop and without demand side response, the frequency continues to drop and system goes into instability. In figure 3, when generation loss occurs the frequency begins to drop because of mismatch of generation and demand. Without demand response and reserves and frequency continues to drop until the system becomes unstable. While in figure 5.4, the frequency is contained at $59 \mathrm{~Hz}$ by switching off the controllable load to stabilize the system and the results shows that with use of demand response the system can be stabilized in case of contingencies. We can estimate the amount of reserves demand side provide by calculating the size of loads contributing in demand response. In this case controllable load in the system is $200 \mathrm{KW}$. So the reserves demand side offers in this case can be estimated at $200 \mathrm{KW}$.

\section{CONCUSLION}

Modern power system has an increased penetration of renewable energy sources, because of its environment friendly benefits. Distributed generation is also increased due to conventional grid difficulties of electrification of rural areas. Renewables are mostly used as D.Gs. Due to increased penetration of these DERs, stability and security of the power system is affected because of its variable nature. Renewable sources are mostly inertia less systems, chances of frequency and voltage fluctuation are great as compared to conventional generators. Frequency instability is most common contingency of increasing penetration of renewable sources. To stabilize frequency there are frequency response reserves, those generators are up and running but they are only connected in case of contingency. So cost of these conventional spinning reserves is high. Demand response can give those frequency reserves at economical cost and without polluting environment. Load can act as frequency reserves at time of contingency. Non sensitive loads can be cut-off in case of emergency to support frequency. Loads can be made sensitive to frequency deviation as frequency deviates from its set points and continues for some time, non-sensitive loads can be shed for some time to restore system frequency. This will help to minimize the amount of spinning reserves and will have economic benefits on economy.

\section{REFERENCES}

[1] U. N. Grid, "Frequency response National Grid," 2015.

[2] M. Aunedi, P. Aristidis Kountouriotis, J. E. Ortega Calderon, D. Angeli, and G. Strbac, "Economic and environmental benefits of dynamic demand in providing frequency regulation," IEEE Trans. Smart Grid, vol. 4, no. 4, pp. 2036-2048, 2013

[3] J. Han and M. A. Piette, "Solutions for Summer Electric Power Shortages : Demand Response and its Applications in Air Conditioning and Refrigerating Systems," Refrig. Air Cond. Electr. Power Mach., vol. 29, no. 1, pp. 1-4, 2008.

[4] N. Boogen, S. Datta, and M. Filippini, "Demand-side management by electric utilities in Switzerland: Analyzing its impact on residential electricity demand," Energy Econ., vol. 64, pp. 402-414, 2017.

[5] M. A. Zehir and M. Bagriyanik, "Demand Side Management by controlling refrigerators and its effects on consumers," Energy Convers. Manag., vol. 64, pp. 238-244, 2012.

[6] K. Pandiaraj, P. Taylor, N. Jenkins, and C. Robb, "Distributed load control of autonomous renewable energy systems," IEEE Trans. Energy Convers., vol. 16, no. 1, pp. 14-19, 2001.

[7] A. Basit, T. Ahmad, A. Y. Ali, K. Ullah, G. Mufti, and A. D. Hansen, "Flexible modern power system: Real-time power balancing through load and wind power," Energies, vol. 12, no. 9, pp. 1-15, 2019.

[8] G. R. Aghajani, H. A. Shayanfar, and H. Shayeghi, "Demand side management in a smart micro-grid in the presence of renewable generation and demand response," Energy, vol. 126, pp. 622-637, 2017.

[9] G. Bazydło and S. Wermiński, "Demand side management through home area network systems," Int. J. Electr. Power Energy Syst., vol. 97, no. August 2017, pp. 174-185, 2018.

[10] J. A. Short, D. G. Infield, and L. L. Freris, "Stabilization of grid frequency through dynamic demand control," IEEE Trans. Power Syst., vol. 22, no. 3, pp. 1284-1293, Aug. 2007.

[11] F. Baccino, F. Conte, S. Grillo, S. Massucco and F. Silvestro, "Frequency Regulation by Management of Building Cooling Systems through Model Predictive Control", In: Power Systems Computation Conference, Wroclaw, Poland, Aug. 2014

[12] A. Molina-García, F. Bouffard, and D. Kirschen, "Decentralized demandside contribution to primary frequency control," IEEE Trans. Pow. Syst., vol. 26, no. 1, pp. 411-419, 2011

[13] Z. Xu, J. Østergaard, and M. Togeby, "Demand as Frequency Controlled Reserve," IEEE Trans. Pow. Syst., vol. 26, no. 3, pp. 1062-1071, Nov. 2011 